\title{
Erratum to: Metallurgical and Mechanical Evaluation of 4340 Steel Produced by Direct Metal Laser Sintering
}

\author{
ELIAS JELIS, ${ }^{1,2}$ MATTHEW CLEMENTE,${ }^{1}$ STACEY KERWIEN, ${ }^{1}$ \\ NUGGEHALLI M. RAVINDRA, ${ }^{2,3}$ and MICHAEL R. HESPOS ${ }^{1}$
}

1.-U.S. Army ARDEC, Picatinny, NJ 07806, USA. 2.-Interdisciplinary Program in Materials, Science \& Engineering, New Jersey Institute of Technology, Newark, NJ 07102, USA. 3.—e-mail: nmravindra@gmail.com

\section{ERRATUM TO: JOM, VOL. 67, NO. 3, 2015 DOI: 10.1007/S11837-014-1273-8}

The authors regret the errors in Table II. An older version of the table was mistakenly submitted for publication and all values have been updated.

Table II. Steel alloy 4340 particle size distribution results using laser diffraction particle analyzer

\begin{tabular}{lr}
\hline Mean size & $33.5 \mu \mathrm{m}$ \\
Median size & $32.9 \mu \mathrm{m}$ \\
Mode size & $32.5 \mu \mathrm{m}$ \\
Standard deviation & $7.7 \mu \mathrm{m}$ \\
D10 & $24.1 \mu \mathrm{m}$ \\
D90 & $43.6 \mu \mathrm{m}$ \\
\hline
\end{tabular}

Line number 18 of the section "Microstructure/ Microhardness" should read as follows:

When the bars were stress relieved at $593.33^{\circ} \mathrm{C}$, the melt pool boundaries were visible (Figs. $7 \mathrm{~b}$ and $c$, and $8 b$ and $c$ ).
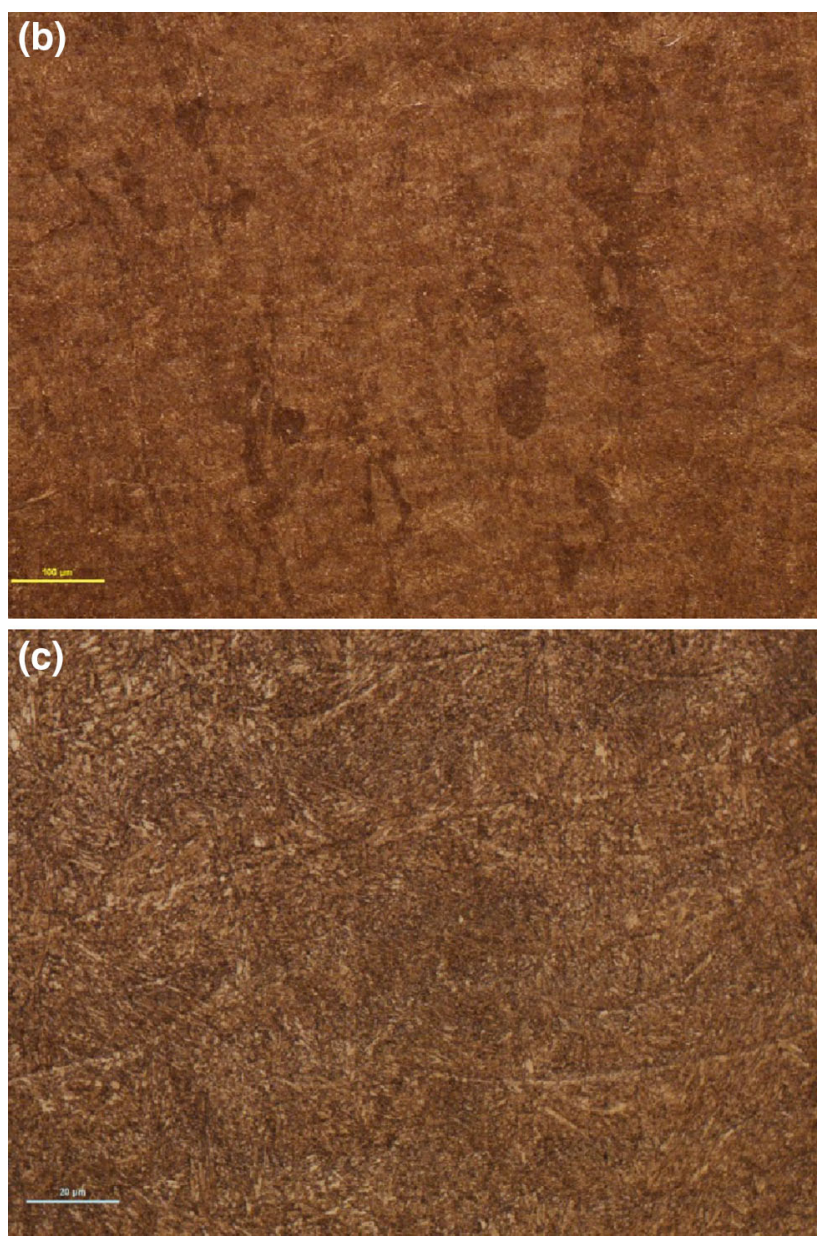

Fig. 7. (b) Optical micrograph of the longitudinal section after stress relief at 100 times magnification; micron marker scale $=100 \mu \mathrm{m}$. (c) Optical micrograph of steel alloy 4340 stress relieved in the longitudinal direction at 500 times magnification; micron marker scale $=20 \mu \mathrm{m}$. 

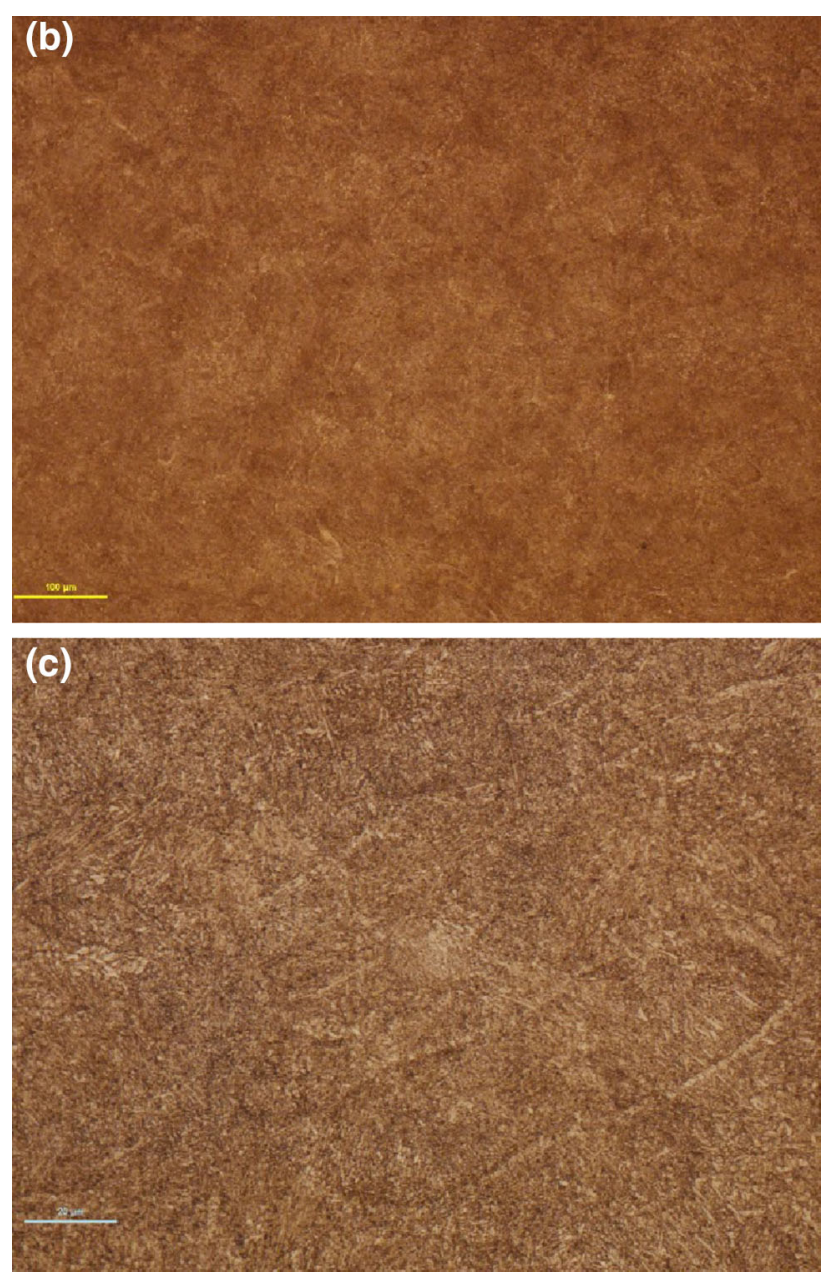

Fig. 8. (b) Optical micrograph of the transverse section after stress relief at 100 times magnification; micron marker scale $=100 \mu \mathrm{m}$. (c) Optical micrograph of steel alloy 4340 stress relieved in the transverse direction at 500 times magnification; micron marker scale $=20 \mu \mathrm{m}$. 